OPEN ACCESS

Edited by:

Jason Luke Parsons,

University of Liverpool,

United Kingdom

Reviewed by:

Gabrielle Grundy,

University of Liverpool,

United Kingdom

Christopher Staples,

Bangor University, United Kingdom

*Correspondence:

Jifeng Feng

doctorffi@163.com

${ }^{\dagger}$ These authors have contributed equally to this work

Specialty section: This article was submitted to Cancer Molecular Targets and Therapeutics,

a section of the journal

Frontiers in Oncology

Received: 07 October 2021 Accepted: 24 November 2021 Published: 16 December 2021

Citation:

Sha H, Gan Y, Zou R, Wu J and Feng J (2021) Research Advances in the Role of the Poly ADP Ribose Polymerase Family in Cancer.

Front. Oncol. 11:790967. doi: 10.3389/fonc.2021.790967

\section{Research Advances in the Role of the Poly ADP Ribose Polymerase Family in Cancer}

\author{
Huanhuan Sha ${ }^{1 \dagger}$, Yujie Gan ${ }^{1 \dagger}$, Renrui Zou ${ }^{1}$, Jianzhong $W u^{2}$ and Jifeng Feng ${ }^{1 *}$ \\ ${ }^{1}$ Department of Chemotherapy, Jiangsu Cancer Hospital, Jiangsu Institute of Cancer Research, The Affiliated Cancer \\ Hospital of Nanjing Medical University, Nanjing, China, ${ }^{2}$ Research Center of Clinical Oncology, Jiangsu Cancer Hospital, \\ Jiangsu Institute of Cancer Research, The Affiliated Cancer Hospital of Nanjing Medical University, Nanjing, China
}

Poly ADP ribose polymerases (PARPs) catalyze the modification of acceptor proteins, DNA, or RNA with ADP-ribose, which plays an important role in maintaining genomic stability and regulating signaling pathways. The rapid development of PARP1/2 inhibitors for the treatment of ovarian and breast cancers has advanced research on other PARP family members for the treatment of cancer. This paper reviews the role of PARP family members (except PARP1/2 and tankyrases) in cancer and the underlying regulatory mechanisms, which will establish a molecular basis for the clinical application of PARPs in the future.

Keywords: PARPs, ADP-ribosylation, cancer, mechanism, biological process

\section{INTRODUCTION}

Poly ADP ribose polymerases (PARPs) are a family of proteins with a homologous catalytic domain involved in ADP-ribosylation (1). ADP-ribosylation refers to the transfer of ADP-ribose to target proteins in a nicotinamide adenine dinucleotide (NAD)-dependent manner. The conjugation of a single ADP-ribose unit onto each modified residue is known as MARylation. Proteins with a single ADP-ribose modification can be further ADP-ribosylated, which is called poly-ADP-ribosylation, and some PARPs are capable of adding multiple ADP-ribose units (PARylation) $(2,3)$. This reversible post-transcriptional modification plays a role in the regulation of various biological processes, such as genomic stability, inflammatory regulation, energy metabolism, apoptosis, and signal transduction (4-6). ADP-ribose can be synthesized and degraded within seconds. The PARdegrading enzyme poly ADP-ribose glycohydrolase hydrolyzes the glycosidic bonds within PAR (7, 8). ADP-ribosylhydrolase 3 (ARH3) hydrolyzes the bond between the protein and the proximal ADP-ribose conjugated at serine residues (9). In addition, several proteins including ARH1, terminal ADP-ribose protein glycohydrolase, and macrodomain-containing 1 and 2 break the ribose-protein bond at different residues (10-12). Histone PARylation factor 1 (HPF1), a PARP1accessory factor, confers serine specificity to the PAR attachment $(13,14)$. DNA and RNA can be ADP-ribosylated as well (15-17). In recent years, the successful development of PARP1/2 inhibitors has provided effective treatment options for ovarian cancer (OC) and breast cancer (BC) (18-21). Moreover, it has caused a great interest in other PARP family members in the field of cancer. PARP3 and PARP9 are overexpressed in different human cancer tissues such as BC, cervical cancer (CC), and diffuse large B-cell lymphoma (DLBCL), whereas PARP7 expression is decreased in cancer tissues (22-26). The biological process of cell proliferation, cell apoptosis, cell migration, and 
invasion are often involved in these cancers. Thus, PARPs can have various functions by targeting different genes involved in biological processes related to cancer. In this review, we summarize the role and regulatory mechanism of PARP3, PARP4, and PARP6-16 in cancer. PARP1/2 and tankyrases are not addressed because they have been reviewed extensively. The expression patterns and functions of these PARPs suggest that other PARP family members are potential targets in cancer.

\section{PARP FAMILY MEMBERS AND CLASSIFICATION}

PARP1 is the first identified member of the PARP family. To date, 17 PARP family members have been identified in humans, and they all possess a conserved domain of approximately 230 amino acids. PARP homologues have been found in other animals, plants, fungi, bacteria, and viruses, which indicates that the function of these enzymes may be widely conserved $(1,2)$. Despite having common domains, they can be classified into four different types according to their special domains or functional characteristics. PARP1 binds to the site of DNA damage and activates the ADP-ribosylation of substrate proteins, which mediate the recruitment of DNA repair factors and the reconstruction of chromosomes around the damaged site (27). PARP2 and PARP3 have similar functions to PARP1, and the presence of PARP3 can promote the damage repair effect of PARP1 (28). Therefore, these three members are classified as DNA-dependent PARPs. PARP5a and PARP5b, which are also known as telomere polymerase 1 (TNKS1) and TNKS2, play an important role in maintaining telomere length and regulating the Wnt and Notch signaling pathways. They belong to the family of tankyrases (29). PARP7, PARP12, and PARP13 have a Cys-CysCys-His zinc-finger domain and are classified as CCCH-type PARPs $(30,31)$. PARP9, PARP14, and PARP15 are classified as macro-type PARPs because they contain a macro domain consisting of approximately 190 amino acid residues (32, 33). The remaining family members are not included in the above four types because they have different structural characteristics and their functions are not clear. Analysis of self ADPribosylation indicates that only PARP1, PARP2, PARP5a, and PARP5b can add multiple ADP-ribose units, whereas the remaining 11 PARPs conjugate a single ADP-ribose to amino acid residues. PARP9 and PARP13 do not have catalytic activity (2). However, when PARP9 is linked to histone E3 ubiquitin ligase $3 \mathrm{~L}$ (DT3XL), it can catalyze the action of mono ADPribosylation (34).

\section{ROLE OF THE PARP FAMILY IN BC}

PARP inhibitors have achieved satisfactory results in the treatment of BC with BRCA1/2 mutation $(35,36)$. This approach is based on the concept of synthetic lethality (37). PARP1/2 inhibitors inactivate base excision repair and cause DNA double-strand breaks (DSBs). In BC cells with BRCA1/2 mutations, DSBs are not repaired by homologous recombination (HR), and their accumulation causes cell death $(37,38)$. In addition, several other PARP members are closely related to the occurrence and development of BC (Table 1). Specifically, PARP3 expression is higher in BC cells of the mesenchymal phenotype and promotes stem-like cell properties in BC cells by inducing the expression of stem cell markers of the sexdetermination-related gene cluster 2 and octamer binding transcription factor 4 and by promoting stem cell self-renewal (39). The expression of PARP3 is higher in BC tissues than in the control group and significantly associated with histological grade. Moreover, PARP3-overexpressing BC patients, especially BRCA1-positive patients, have shorter disease-free survival (22). Beck et al. showed that PARP3 ADP-ribosylates glycogen synthase kinase-3 $\beta$, a positive regulator of rapamycininsensitive companion of TOR (Rictor) ubiquitination and degradation $(44,45)$. The Rictor/mammalian target of rapamycin complex 2 (Rictor/mTORC2) pathway is involved in cell proliferation, survival, and epithelial-to-mesenchymal transition (EMT) (46). PARP3 selectively suppresses the

TABLE 1 | Role of PARP family in BC.

\begin{tabular}{|c|c|c|c|c|}
\hline Member & Expression/Germline Variants/Status & $\begin{array}{l}\text { Biological } \\
\text { Process }\end{array}$ & Clinicopathological Parameters & Reference \\
\hline PARP3 & $\begin{array}{l}\text { Higher (cancer cells of mesenchymal-like basal B subtype } \\
\text { vs epithelial-like luminal subtypes) }\end{array}$ & $\begin{array}{l}\text { Cell self- } \\
\text { renewal }\end{array}$ & - & (39) \\
\hline PARP3 & Higher (cancer tissues vs tumor-adjacent tissues) & - & $\begin{array}{l}\text { Overexpression associated with histological grade II-III, shorter } \\
\text { DFS time and exhibited a tendency toward shorter OS }\end{array}$ & (22) \\
\hline PARP4 & $\begin{array}{l}\text { Higher frequency (G496V and T1170I) (cancer participants } \\
\text { vs the controls) }\end{array}$ & $\begin{array}{l}\text { Cell } \\
\text { proliferation }\end{array}$ & $\begin{array}{l}\text { Low expression associated with poor PFS and OS (GEO, EGA, } \\
\text { and TCGA datasets) }\end{array}$ & $(40)$ \\
\hline PARP7 & Lower (tumor tissues vs normal tissues) & - & $\begin{array}{l}\text { Higher expression related to preferable survival (all available } \\
\text { databases online at that time) }\end{array}$ & (25) \\
\hline PARP7 & - & $\begin{array}{l}\text { Cell } \\
\text { proliferation }\end{array}$ & Lower expression associated with worse prognosis & $(41)$ \\
\hline PARP9 & Higher (ER ${ }^{+}$-tumor tissues vs tumor-adjacent tissues) & - & - & $(42)$ \\
\hline PARP9 & Higher (cancer tissues vs paired normal breast tissues) & $\begin{array}{l}\text { Cell } \\
\text { migration }\end{array}$ & $\begin{array}{l}\text { Overexpression negatively associated with ER expression, } \\
\text { positively associated with axillary lymph node metastasis }\end{array}$ & $(43)$ \\
\hline
\end{tabular}

BC, breast cancer; DFS, disease-free survival; OS, overall survival; PFS, progression-free survival; GEO, Gene Expression Omnibus; EGA, European Genome-phenome Archive; TCGA, The Cancer Genome Atlas; ER, estrogen receptor. 
growth, survival, and in vivo tumorigenicity of BRCA1-deficient triple-negative BC (TNBC) cells. Therefore, PARP3 and BRCA1 are synthetic lethal, and targeting the catalytic activity of PARP3 might be a promising therapeutic strategy for BRCA1-associated cancers (44). In addition, PARP3 inhibitors sensitize BC cells to vinorelbine, a drug used in the treatment of metastatic $\mathrm{BC}$. These results indicate that combination treatment with PARP3 inhibitors and vinorelbine is a promising strategy for $\mathrm{BC}$ patients with metastases (47).

Whole-exome sequencing showed that the frequencies of the PARP4 variants, G496V and T1170I, are significantly higher in BC tissues. Survival analysis shows that low expression of PARP4 is correlated with poor progression-free survival (PFS) and overall survival (OS), suggesting that PARP4 functions as a tumor suppressor in BC (40). However, the results of functional analyses do not support the role of PARP4 as a susceptibility gene, emphasizing the importance of functional analysis for verifying candidate cancer susceptibility genes (48). In BC cells, PARP6 regulates the activity of cycle checkpoint kinase 1 (Chk1), a key downstream factor in the ataxia telangiectasia and Rad3-related (ATR) pathway (49), via ADPribosylation, thereby maintaining centrosome integrity and ultimately promoting the development of BC $(50,51)$. PARP7 expression is lower in $\mathrm{BC}$ tissues than in normal tissues, and its downregulation is associated with worse prognosis $(25,41)$. Recent studies suggest that estrogen receptor $\alpha(E R \alpha)$, the dominant regulator of estrogen action in breast tissue, regulates PARP7 expression and that PARP7 acts as a negative regulator of $\mathrm{ER} \alpha$ activity via mono-ADP-ribosylation in $\mathrm{BC}$ cells $(52,53)$. By contrast, PARP9 expression is higher in BC than in paired normal breast tissues, and its expression is positively correlated with axillary lymph node metastasis and negatively associated with ER expression. These data suggest that PARP9 promotes the progression of $\mathrm{BC}(42,43)$. In addition to the above PARP family members, PARP13 is also involved in mammary tumorigenesis. Heat shock transcription factor 1 recruits PARP1 through PARP13. The ternary complex formation protects cells from DNA damage by promoting DNA repair, and supports the growth of BRCA1-null mammary tumors (54).

\section{ROLE OF THE PARP FAMILY IN MALIGNANCIES OF THE DIGESTIVE SYSTEM}

\section{Role of the PARP Family in Esophageal Cancer and Gastric Cancer}

The PARP family plays an important role in gastrointestinal tumors (Table 2). Single-cell intratumoral stemness analysis revealed that PARP4 is a cancer stemness-associated gene in esophageal squamous cell carcinoma (ESCC). In a cohort of 121 patients with ESCC, immunohistochemical scoring indicated that high PARP4 expression is associated with poorer survival (65). The expression of PARP9 is upregulated in EC tissues and EC cells and may be regulated by circular RNA PRKCI (circPRKCI), affecting the viability, colony formation, cell cycle progression, and radiosensitivity of EC cells (55). In GC, PARP6 expression is higher in cancer tissues and cells than in normal gastric mucosa tissues and cells. PARP6 promotes cell proliferation, migration, and invasion of GC cells partly by activating survivin (56), a member of the inhibitor of apoptosis protein family (66). Analysis of an online database indicated that PARP10 expression increases survival in GC and showed that PARP10 is involved in the regulation of fatty acid degradation, promoting further studies to understand of the role of PARP10

TABLE 2 | Role of PARP family in digestive system tumor

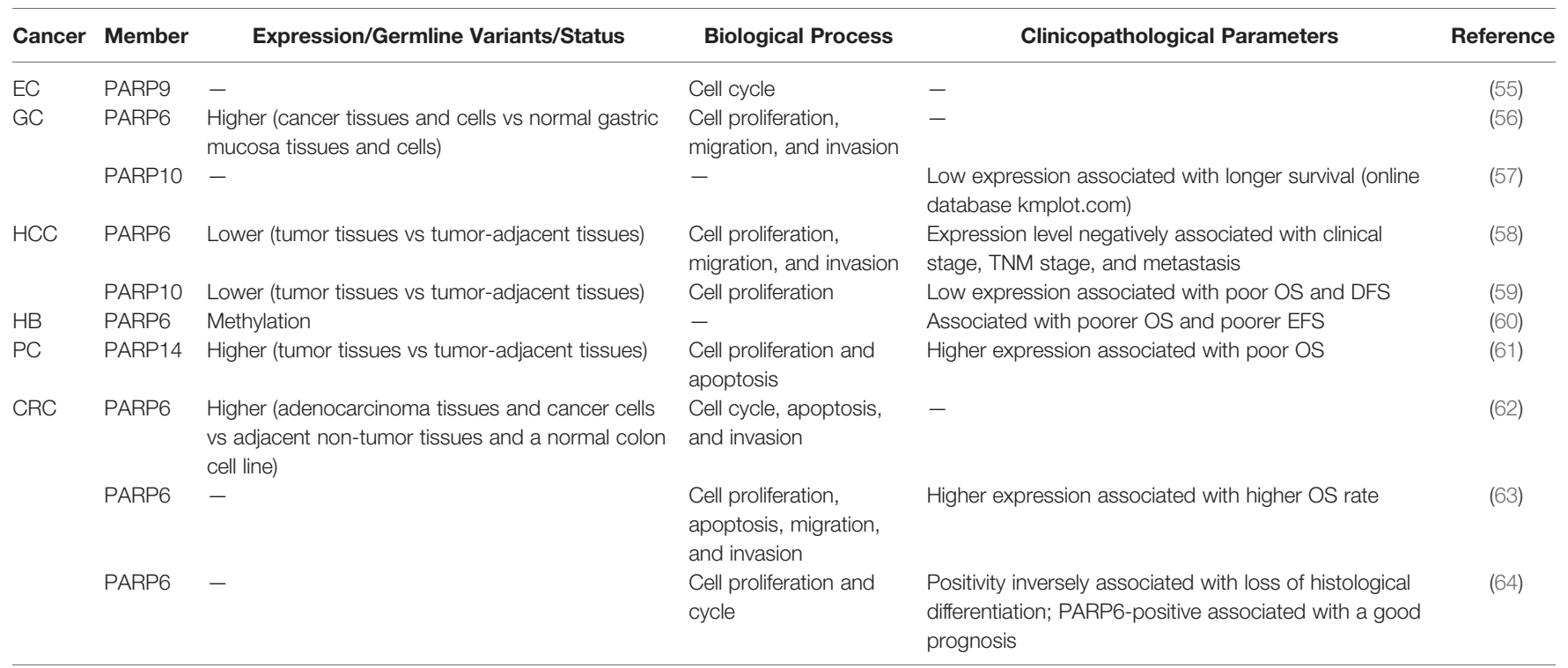

EC, esophageal cancer; GC, gastric carcinoma; HCC, hepatocellular carcinoma; TNM, Tumor, Node, Metastasis; OS, overall survival; DFS, disease-free survival; HB, hepatoblastoma; EFS, event-free survival; $P C$, pancreatic cancer; $C R C$, colorectal cancer. 
in metabolic regulation (57). Most of these studies focused on the relationship between PARP expression and clinical characteristics, and few studies performed functional analyses. Further studies are needed to clarify the roles of these PARPs in $\mathrm{EC}$ and GC in the future.

\section{Role of the PARP Family in Hepatic Tumors and Pancreatic Cancer}

The role of PARP6 in hepatocellular carcinoma (HCC) cells is inconsistent with that in GC. It is expressed at a low level in tumor tissues and is negatively correlated with clinical stage in
HCC. Moreover, PARP6 inhibits the expression of X-ray repair cross complementing 6 (XRCC6) by inducing its degradation, thereby affecting the $\mathrm{Wnt} / \beta$-catenin signaling pathway and ultimately inhibiting the occurrence and development of HCC (58). PARP10 delays the progression of HCC (Figure 1A). Zhao et al. demonstrated that PARP10 expression is lower in metastatic cancer tissues than in primary cancer tissues and adjacent tissues (67). Aurora-A is a serine/threonine kinase that is overexpressed in multiple human cancers and involved in tumor cell migration and invasion $(68,69)$. PARP10 inhibits the kinase activity of Aurora-A by ADP-ribosylation, thereby
A

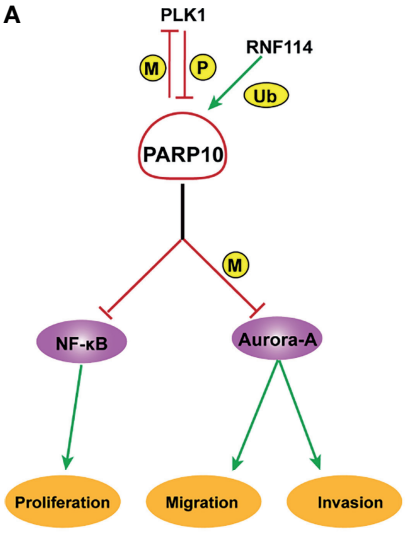

C

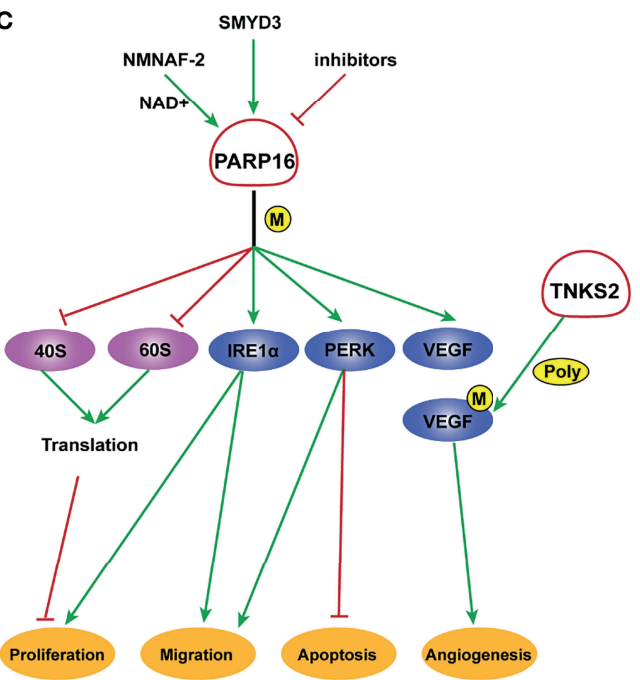

B

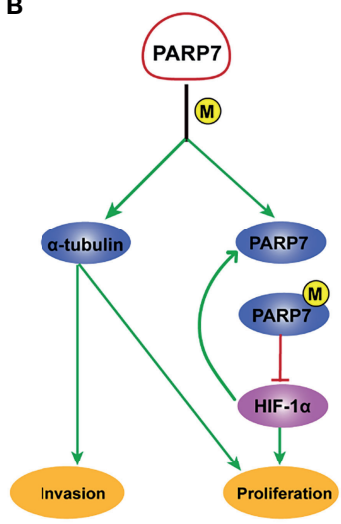

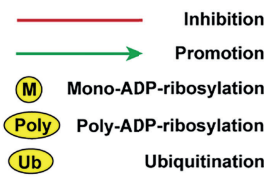

(Ub)

D

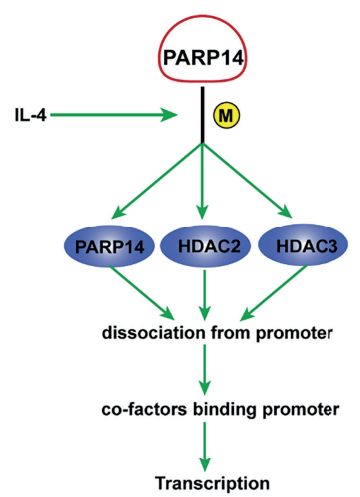

FIGURE 1 | Molecular mechanism of PARP7, PARP10, PARP14, and PARP16 ADP-ribosylation. (A) PLK1 phosphorylates PARP10 and disrupts its inhibition of NEMO ubiquitination, thereby enhancing the transcriptional activity of NF- $\mathrm{kB}$. In turn, PARP10 mono-ADP-ribosylates PLK1, whose kinase activity and oncogenic function are significantly inhibited by MARylation. RNF114 promotes the ubiquitination of PARP10, and PARP10 mono-ADP-ribosylates Aurora-A and inhibits its kinase activity, thereby playing an important role in tumor proliferation and metastasis suppression. (B) PARP-7 MARylates $\alpha$-tubulin to promote microtubule instability, which may regulate cancer cell growth and motility. HIF-1 promotes the transcription of PARP7, which serves to deactivate HIF-1 in an ADP ribosylationdependent manner. (C) A potential inhibitor of PARP16 suppresses the ER stress-induced phosphorylation of PERK and IRE1 $\alpha$, thereby increasing cancer cell apoptosis. SMYD3 can bind to the promoter of PARP16 and activate its transcription, increasing cell proliferation and invasion. NMNAT-2 supports the catalytic activity of PARP16, which MARylates ribosomal proteins. Ribosome MARylation promotes protein homeostasis in cancers by fine-tuning the levels of protein synthesis and preventing toxic protein aggregation. In addition, PARP16 mono ADP-ribosylates VEGF, which is further poly ADP-ribosylated by TNKS-2, leading to the activation of downstream pathways that promote angiogenesis. (D) PARP14 mono-ADP-ribosylates HDAC2, HDAC3, and itself with IL-4 occurrence, which facilitates the dissociation of PARP14 and HDAC complex from the promoter, leading to the binding of transcription co-factors to the promoter and initiating gene transcription. 
regulating its downstream signals related to metastasis (67). Furthermore, PARP10 phosphorylation at T601 by polo-like kinase 1 (PLK1) suppresses its inhibition of nuclear factor kappa-B (NF- $\mathrm{KB})$ essential modulator (NEMO) ubiquitination, which increases the transcriptional activity of NF- $\mathrm{KB}$ toward multiple target genes. PLK1 is mono-ADP-ribosylated by PARP10, which inhibits its kinase activity and oncogenic function in HCC (59). These findings identify a PLK1/ PARP $10 / \mathrm{NF}-\kappa \mathrm{B}$ signaling axis and suggest potential therapeutics for PARP10-expressing HCC. PARP12 also acts as a cancer suppressor in HCC by regulating the stability of fourand-a-half LIM-only protein 2 (FHL2) (70). FHL2 is a negative regulator of transforming growth factor $\beta 1$ (TGF- $\beta 1$ ), a potent EMT driver that plays critical roles in the EMT process (71-73). Therefore, PARP12 suppresses HCC metastasis by negatively regulating TGF- $\beta 1$ expression via FHL2 (70). By contrast, PARP14 promotes the development of HCC by inhibiting cJun N-terminal kinase 1 (JNK1), which phosphorylates and activates pyruvate kinase M2 (PKM2), thus maintaining low activity of PKM2 and promoting aerobic glycolysis in HCC (74). This study provided a mechanistic link between PARP14, cancer cell apoptosis, and metabolism.

Hepatoblastoma $(\mathrm{HB})$ is very rare but the most common malignant neoplasm of the liver. PARP6 is methylated in HB and significantly associated with poor OS, suggesting that it could be a useful molecular marker to predict a poor outcome in $\mathrm{HB}$ patients (60). PC has one of the worst prognoses among different cancer types. The PARP inhibitor olaparib is associated with a longer PFS in patients with advanced PC with BRCA1/2 mutation (75). In addition, PARP4 and PARP14 might play a significant role in PC as well. Alimirzaie et al. suggested that PARP4 is a potential candidate gene for susceptibility to PC (76). PARP14 is highly expressed in primary PC specimens and significantly associated with poor prognosis. PARP14 promotes cell proliferation and gemcitabine resistance in PC cells through the NF- $\mathrm{KB}$ signaling pathway, indicating its potential role as a therapeutic target for PC (61).

\section{Role of the PARP Family in Colorectal Cancer and Colorectal Neuroendocrine Tumors}

Several PARP family members play a role in CRC. A gene set meta-analysis identified PARP4 as a candidate prognostic factor for CRC metastasis (77). In addition, the PARP4 ${ }^{\mathrm{V} 458 \mathrm{I}}$ mutation is only detected in patients with liver metastasis and results in dysregulated protein abundance (78). Proteogenomics analysis showed that PARP4 copy number is markedly increased in CRC (79). Colorectal NETs are rare neoplasms, and Wang et al. found two missense mutations (rs77269056 and rs73172125) in the PARP4 gene, suggesting that PARP4 is a candidate gene involved in colorectal NETs (80). The results of these exploratory analyses need to be confirmed, and functional experiments demonstrating the role PARP4 in CRC or in colorectal NETs need to be performed.

The role of PARP6 in CRC is controversial. PARP6 expression is higher in well-differentiated CRC tissues, and
PARP6 positivity is negatively correlated with the expression of Ki-67, a proliferation index. Survival analyses show that PARP6positive patients have a better prognosis. Based on these results, Tuncel et al. proposed that PARP6 might be a cancer suppressor (64). Furthermore, PARP6 plays an inhibitory role by downregulating the expression of survivin in CRC (63). However, another study showed that the expression levels of PARP6 and survivin are higher in colorectal adenocarcinoma tissues and cells than in adjacent tissues and normal intestinal mucosal cells. PARP6 downregulation inhibits cell survival and invasion and induces G0/G1 arrest and apoptosis (62). These contradictory results could be attributed to the use of samples from different stages or different cell models. The role of PARP6 in CRC remains controversial and needs further investigation.

PARP7 and PARP10 are also involved in CRC. Stable knockdown of PARP7 caused the CRC cell line HCT116 to proliferate significantly faster than control cells. PARP7 downregulates hypoxia-inducible factor $1 \alpha$ (HIF-1 $\alpha$ ), which is crucial for the adaptive responses of tumors to changes in oxygenation and is often overexpressed in cancers in an ADPribosylation dependent manner (41) (Figure 1B). PARP10 shows an inconsistent effect on CRC cell lines. Inhibition of the enzymatic activity of PARP10 led to cell cycle arrest accompanied by a marked decrease in proliferative ability (81). Taken together, these results support the importance of these two PARPs in CRC.

\section{ROLE OF THE PARP FAMILY IN UROGENITAL NEOPLASMS}

PARP inhibitors have markedly changed the treatment of OC (82-84). In addition to PARP1/2, other PARP molecules play important roles in OC. Tumors from high-grade serous ovarian cancer (HGSOC) patients who are platinum-resistant have a distinct molecular profile characterized by increased expression of PARP4. This indicates that PARP4 may be a candidate actionable target for platinum-resistant HGSOC (85). However, similar to CRC or colorectal NETs, the role of PARP4 in OC has not been validated with strong experimental evidence. A genome-wide association study suggested a functional role for PARP7 in OC development. PARP7 is markedly downregulated in OC cells compared with primary human ovarian surface epithelial (POE) cells. Similarly, the level of PARP7 expression is lower in OC tissues than in ovary normal tissues (86) (Table 3). Goode et al. found that PARP7 MARylates $\alpha$-tubulin to promote microtubule instability, thereby contributing to several cancer-related biological endpoints such as growth and motility of OC cells although PARP7 mRNA levels are lower in OC patient samples than in non-cancerous tissue (26) (Figure 1B). This study identified a large number of PARP7 protein substrates, which may stimulate efforts to expand studies of this PARP molecule. Unlike PARP7, PARP10 expression is upregulated in OC patients (Table 3), with $42 \%$ of the cohort showing platinum sensitivity and $9 \%$ showing resistance (87). This suggests a possible role for PARP10 as a predictor of the 
TABLE 3 | Role of PARP family in gynecological tumor.

\begin{tabular}{|c|c|c|c|c|c|}
\hline Cancer & Member & Expression/Germline Variants/Status & Biological Process & Clinicopathological Parameters & Reference \\
\hline \multirow[t]{3}{*}{ OC } & PARP7 & $\begin{array}{l}\text { Lower (cancer tissues from TCGA vs ovary normal } \\
\text { tissues from GTEx) }\end{array}$ & $\begin{array}{l}\text { Cell proliferation and } \\
\text { invasion }\end{array}$ & - & $(26)$ \\
\hline & PARP7 & Lower (cancer cells vs POE cells) & - & - & (86) \\
\hline & PARP10 & Higher (cancer tissues vs normal tissues from TCGA) & - & $\begin{array}{l}\text { Expression associated with sensitivity to carboplatin } \\
\text { and rucaparib }\end{array}$ & $(87)$ \\
\hline $\mathrm{CC}$ & PARP9 & Higher (cancer tissues vs normal tissues) & $\begin{array}{l}\text { Cell proliferation and } \\
\text { invasion }\end{array}$ & - & (23) \\
\hline
\end{tabular}

OC, ovarian cancer; TCGA, The Cancer Genome Atlas; GTEx, Genotype-Tissue Expression; POE, primary human ovarian surface epithelial; CC, cervical cancer.

response to platinum-based agents. PARP16 also affects OC cell proliferation. The catalytic activity of PARP16 is supported by nicotinamide mononucleotide adenylyl-transferase 2 (NMNAT2), which is highly upregulated in OC. Depletion of NMNAT-2 or PARP16 decreases the growth of OC cells (88) (Figure 1C).

PARP family members also play a role in $\mathrm{CC}$ and prostate cancer. PARP9 expression is higher in CC patients than in controls (Table 3). The long non-coding RNA small nucleolar RNA host gene 16 (SNHG16) recruits SPI1 to promote transcription of PARP9 in CC cells. PARP9 downregulation inhibits proliferation and invasion of CC cells (23). Schleicher et al. found that PARP10 promotes cell proliferation, and its overexpression alleviates cellular sensitivity to replication stress. Loss of PARP10 decreases the tumorigenic activity of HeLa cells (89). A recent study demonstrated that PARP10 is regulated by RNF114 and functions as a tumor metastasis suppressor in CC cells (90) (Figure 1A). ADP-ribosylation of PARP10 is decreased in RNF114-knockout cells, accompanied by a decrease of Aurora A, a substrate involved in HCC (67). This suggests that RNF114 regulates PARP10 activity, which might in turn inhibit Aurora A activity and downstream signaling. PARP13 acts as a key regulator of the cellular response to tumor necrosis factor-related apoptosis-inducing ligand (TRAIL), a pro-apoptotic cytokine (91). TRAIL binds to its receptors TRAILR1-4. TRAIL binding to TRAILR1 and TRAILR2 triggers the extrinsic apoptotic pathway, whereas TRAILR3 and TRAILR4 act as pro-survival decoy receptors (92-96). PARP13 destabilizes TRAILR4 mRNA post-transcriptionally by binding to its $3^{\prime}$ untranslated region, although it has no effect on the levels of TRAILR1-3. Therefore, PARP13 shifts the balance in the TRAIL signaling pathway towards decreased anti-apoptotic signaling and increased cell sensitivity to TRAIL-mediated apoptosis in HeLa cells (91). PARP16 regulates the unfolded protein response (UPR) of the endoplasmic reticulum (ER). UPR is an ER stress-sensing/repair pathway involved in cell survival and tumor progression (97-99). Inhibition of PARP16 suppresses UPR-related genes, resulting in a dramatic increase of $\mathrm{HeLa}$ cell apoptosis (Figure 1C). A combination of a PARP16 inhibitor and ER stress-inducing agents might represent a novel approach for cancer therapy (100). Furthermore, PARP16 is a target gene for SET and MYND domain containing 3 (SMYD3), a lysine methyltransferase, and SMYD3 may bind to the promoter of PARP16 to activate host gene transcription (101) (Figure 1C). ER-associated PARP16 mono ADP-ribosylates vascular endothelial growth factor (VEGF), the major cytokine regulating angiogenesis, and mono ADP-ribosylated VEGF is poly ADP-ribosylated by Golgi TNKS-2 in HeLa cells, finally leading to angiogenesis (102) (Figure 1C). This finding provides evidence of the interplay between PARPs in different organelles.

In metastatic prostate cancer cells, PARP9 and PARP14 were identified as novel oncogenic survival factors. Mechanistically, DTX3L forms a complex with PARP9 and PARP14 and mediates the proliferation as well as drug resistance of prostate cancer cells. Moreover, it was demonstrated for the first time that the enzymatic activity of PARP14 is necessary for the survival of prostate cancer cells (103). Therefore, combined targeted inhibition of PARP14, PARP9, and/or DTX3L might represent a novel therapeutic approach.

\section{ROLE OF THE PARP FAMILY IN MALIGNANCIES OF HEMATOLOGIC AND LYMPHATIC SYSTEMS}

PARP9, also termed BAL1 (B-aggressive lymphoma), is expressed at significantly higher levels in fatal high-risk diffuse large B-cell lymphoma (DLBCL) than in low-risk tumors (Table 4). PARP9 promotes malignant B-cell migration (24) and is constitutively expressed in a subset of high-risk DLBCLs with an active host inflammatory response. Interferon (IFN) induces PARP9 expression in DLBCL cell lines, and PARP9 is involved in IFNrelated signaling pathways, as indicated by the effect of doxycyclineinduced BAL1 on upregulating multiple IFN-stimulated genes (109). Although PARP9 has no ADP-ribosylation activity, it interacts with signal transducer and activator of transcription 1 (STAT1) through its macro domains in an ADP-ribosylationdependent manner. As a consequence, PARP9 mediates proliferation, survival, and chemoresistance in DLBCL by repressing the anti-proliferative and pro-apoptotic IFN-STAT1IRF1-p53 axis (110). PARP14 and PARP15 also belong to the BAL family and have an effect on lymphoma (33). The effect of interleukin 4 (IL-4) on increasing glycolysis in B cells requires PARP14. Suppression of apoptosis is central to B-lymphoid oncogenesis, and elevated macro-PARP expression is correlated with lymphoma aggressiveness (111). Furthermore, PARP14 alters IL-4 and STAT6-dependent transcription, which plays an important role in B cell responses. In the presence of IL-4, PARP14 promotes efficient ADP-ribosylation of histone deacetylases (HDACs) and itself, leading to the release of HDACs from the promoter to activate transcription (112) (Figure 1D).

High expression of PARP9 is associated with poor survival in acute myeloid leukemia (AML) patients (Table 4) (104). 
TABLE 4 | Role of PARP family in malignancies of hematologic and lymphatic systems and in other tumors.

\begin{tabular}{|c|c|c|c|c|c|}
\hline Cancer & Member & Expression/Germline Variants/Status & $\begin{array}{l}\text { Biological } \\
\text { Process }\end{array}$ & Clinicopathological Parameters & Reference \\
\hline DLBCL & PARP9 & Higher (high-risk tumors vs low-risk tumors) & Cell migration & - & $(24)$ \\
\hline \multirow[t]{2}{*}{ AML } & PARP9 & $\begin{array}{l}\text { Higher (cancer tissues from TCGA vs normal tissues } \\
\text { from GTEx) }\end{array}$ & - & - & $(104)$ \\
\hline & PARP15 & rs6793271, rs17208928 & - & Two polymorphisms associated with increased OS & $(105)$ \\
\hline MM & PARP14 & Higher (cancer cells vs normal B cells) & Cell apoptosis & $\begin{array}{l}\text { High expression associated with disease progression and } \\
\text { poor survival }\end{array}$ & $(106)$ \\
\hline LUAD & PARP15 & - & - & Expression associated with better prognosis & $(107)$ \\
\hline GBM & PARP3 & Higher (tumor tissues vs tumor-adjacent tissues) & Cell proliferation & High expression associated with cell radioresistance & $(108)$ \\
\hline
\end{tabular}

DLBCL, diffuse large B-cell lymphoma; AML, acute myeloid leukemia; TCGA, The Cancer Genome Atlas; GTEx, Genotype-Tissue Expression; OS, overall survival; MM, multiple myeloma; LUAD, lung adenocarcinoma; GBM, glioblastomas.

In addition, two polymorphisms of PARP15 are associated with increased OS in AML (105), suggesting that PARP15 is a potential therapeutic target in AML. The development of tyrosine kinase inhibitors (TKI) has greatly improved the treatment of chronic myeloid leukemia (CML). Islam et al. performed whole-exome sequencing of DNA to reveal genetic variants, which were potential markers for predicting the prognosis of CML patients after TKI discontinuation. PARP9 was one of the markers identified, and its sensitivity, specificity, and positive as well as negative predictive values were verified (113). In multiple myeloma (MM) (Table 4), Barbareulo showed that c-Jun Nterminal kinase 2 (JNK2) constitutively suppresses JNK1mediated apoptosis by affecting expression of PARP14. Moreover, inhibition of PARP14 enhances the sensitization of MM cells to anti-myeloma agents. These authors also found that PARP14 is highly expressed in myeloma plasma cells and associated with poor survival (106). These findings identify PARP14 as a potential therapeutic target in MM. In fact, targeting PARP14 has been proposed as a possible therapeutic approach for not only MM but also multiple cancer types, and PARP14 inhibitors are currently being developed (114). In addition to the aforementioned mechanisms, PARP14 was previously reported to be essential for genomic stability by promoting $\mathrm{HR}$ and alleviating replication stress through the regulation of an essential HR factor, RAD51 (115). Subsequently, Moldovan et al. also found that the ATR-Chk1 pathway is essential for the viability of PARP14-deficient cells. PARP14-deficient cells are hypersensitive to both genetic depletion and pharmacological inhibition of this pathway, which is similar to the concept of "synthetic lethality" of existing PARP inhibitors (116). The association between Chk1 and PARP6 has been reported in BC as well (50), highlighting the importance of the ATR-Chk1 pathway and providing further evidence supporting PARPs as potential therapeutic targets in cancer.

\section{ROLE OF THE PARP FAMILY IN OTHER CANCERS}

Telomere function and DNA damage response pathways are frequently inactivated in cancer. An analysis of 83 non-small-cell lung cancer (NSCLC) tissues and the corresponding control samples indicated that telomere attrition is associated with poor clinical outcomes. Tumors with reactivated telomerase are characterized by downregulation of genes related to DNA repair such as PARP3 (117). This suggests that the relationship between telomerase activity and the loss of several DNA repair genes is involved in the pathogenesis of NSCLC. Additionally, PARP15 is a tumor-infiltrating B lymphocyte-specific gene (TILBSig) that is highly associated with OS (Table 4). TILBSigs serve as excellent predictors of the response to immunotherapy and radiotherapy in lung adenocarcinoma patients (107). PARP7 MARylates TANK binding kinase 1 , a major kinase related to the activation of the type I IFN response and antiviral immunity, thereby repressing the type I IFN response. Cancer cells may use PARP7 as a mechanism to evade the host immune system by suppressing the type I IFN response, thereby validating $\mathrm{T}$ cellmediated antitumor immunity $(118,119)$. A recent study showed that oral administration of the PARP7 small-molecule inhibitor RBN-2397 induces antitumor immunity and causes complete tumor regression in a lung cancer xenograft by increasing IFN signaling; a phase 1 clinical trial of RBN-2397 is underway (120, 121). These studies indicate that PARP7 is an important contributor to cancer development. PARP3 is upregulated in primary glioblastoma (GBM) (Table 4). Inhibition of PARP3 expression decreases the proliferation of GBM cells and has a synergistic sensitization effect in combination with radiotherapy by interacting with forkhead box M1, enhancing its transcriptional activity (108). Studies in different cancer types suggest the important roles of some PARP family members, although additional studies are needed.

\section{CONCLUSION AND PROSPECTS}

Compared with PARP1/2, other members of the PARP family have been investigated in a limited number of studies; however, their importance in cancer has attracted increased attention in recent years. Studies have highlighted the crucial role of PARPs in the occurrence and progression of human cancer. Dysregulation of PARPs has been demonstrated in a wide range of cancer types, and their differential expression indicates their dual regulatory effects on human cancer. PARP3, PARP9, and PARP14 are usually overexpressed in tumors, whereas PARP7 is normally downregulated. PARP6 and PARP10 have both promoting and suppressive effects on cancer development. Mechanistically, they 
are widely involved in multiple biological processes, including cell proliferation, apoptosis, migration, and invasion. In addition, they participate in the response of cancers to both chemoand radiotherapy.

Given the crucial function of PARPs in cancer initiation and progression, therapies targeting PARPs might be promising. However, larger scale studies are needed, as some of the studies focus on clinical relevance, and few have performed functional assays on cells or animal models. Although the biological functions of some PARPs have been validated, the mechanisms underlying the effects often remain unclear. Furthermore, the subcellular localization, biological function, and mechanism of some members of the PARP family such as PARP8 remain unknown in cancer. Additional comprehensive studies are needed to fully elucidate the function of each member of this family.

\section{REFERENCES}

1. Vyas S, Chesarone-Cataldo M, Todorova T, Huang YH, Chang P. A Systematic Analysis of the PARP Protein Family Identifies New Functions Critical for Cell Physiology. Nat Commun (2013) 4:2240. doi: 10.1038/ ncomms 3240

2. Hottiger MO. SnapShot: ADP-Ribosylation Signaling. Mol Cell (2015) 58 (6):1134-el. doi: 10.1016/j.molcel.2015.06.001

3. Perina D, Mikoč A, Ahel J, Ćetković H, Žaja R, Ahel I. Distribution of Protein Poly(ADP-Ribosyl)Ation Systems Across All Domains of Life. DNA Repair (2014) 23:4-16. doi: 10.1016/j.dnarep.2014.05.003

4. Miwa M, Masutani M. PolyADP-Ribosylation and Cancer. Cancer Sci (2007) 98(10):1528-35. doi: 10.1111/j.1349-7006.2007.00567.x

5. Scarpa ES, Fabrizio G, Di Girolamo M. A Role of Intracellular Mono-ADPRibosylation in Cancer Biology. FEBS J (2013) 280(15):3551-62. doi: $10.1111 /$ febs.12290

6. Palazzo L, Ahel I. PARPs in Genome Stability and Signal Transduction: Implications for Cancer Therapy. Biochem Soc Trans (2018) 46(6):1681-95. doi: 10.1042/BST20180418

7. Slade D, Dunstan MS, Barkauskaite E, Weston R, Lafite P, Dixon N, et al. The Structure and Catalytic Mechanism of a Poly(ADP-Ribose) Glycohydrolase. Nature (2011) 477(7366):616-20. doi: 10.1038/nature10404

8. Dunstan MS, Barkauskaite E, Lafite P, Knezevic CE, Brassington A, Ahel M, et al. Structure and Mechanism of a Canonical Poly(ADP-Ribose) Glycohydrolase. Nat Commun (2012) 3:878. doi: 10.1038/ncomms1889

9. Fontana P, Bonfiglio JJ, Palazzo L, Bartlett E, Matic I, Ahel I. Serine ADPRibosylation Reversal by the Hydrolase ARH3. eLife (2017) 6:e28533. doi: $10.7554 /$ eLife. 28533

10. Kato J, Zhu J, Liu C, Moss J. Enhanced Sensitivity to Cholera Toxin in ADPRibosylarginine Hydrolase-Deficient Mice. Mol Cell Biol (2007) 27 (15):5534-43. doi: 10.1128/MCB.00302-07

11. Rosenthal F, Feijs KL, Frugier E, Bonalli M, Forst AH, Imhof R, et al. Macrodomain-Containing Proteins Are New Mono-ADP-Ribosylhydrolases. Nat Struct Mol Biol (2013) 20(4):502-7. doi: 10.1038/nsmb.2521

12. Jankevicius G, Hassler M, Golia B, Rybin V, Zacharias M, Timinszky G, et al. A Family of Macrodomain Proteins Reverses Cellular Mono-ADPRibosylation. Nat Struct Mol Biol (2013) 20(4):508-14. doi: 10.1038/ nsmb. 2523

13. Gibbs-Seymour I, Fontana P, Rack JGM, Ahel I. HPF1/C4orf27 Is a PARP-1Interacting Protein that Regulates PARP-1 ADP-Ribosylation Activity. Mol Cell (2016) 62(3):432-42. doi: 10.1016/j.molcel.2016.03.008

14. Suskiewicz MJ, Zobel F, Ogden TEH, Fontana P, Ariza A, Yang JC, et al. HPF1 Completes the PARP Active Site for DNA Damage-Induced ADPRibosylation. Nature (2020) 579(7800):598-602. doi: 10.1038/s41586-0202013-6

15. Talhaoui I, Lebedeva NA, Zarkovic G, Saint-Pierre C, Kutuzov MM, Sukhanova MV, et al. Poly(ADP-Ribose) Polymerases Covalently Modify
In conclusion, PARPs are involved a variety of cancer biological characteristics, suggesting their potential in cancer diagnosis, prognosis, and treatment. Nevertheless, extensive research is still needed before the application of PARP-based diagnostic and therapeutic strategies to the clinic.

\section{AUTHOR CONTRIBUTIONS}

All authors participated in the discussion of the draft. HS and YG: Writing-original draft. RZ and JW: Validation and writingrevision and editing. JF: Conceptualization, supervision, and project administration. All authors contributed to the article and approved the submitted version.

Strand Break Termini in DNA Fragments In Vitro. Nucleic Acids Res (2016) 44(19):9279-95. doi: 10.1093/nar/gkw675

16. Matta E, Kiribayeva A, Khassenov B, Matkarimov BT, Ishchenko AA Insight Into DNA Substrate Specificity of PARP1-Catalysed DNA Poly (ADP-Ribosyl)Ation. Sci Rep (2020) 10(1):3699. doi: 10.1038/s41598-02060631-0

17. Weixler L, Scharinger K, Momoh J, Luscher B, Feijs KLH, Zaja R ADP-Ribosylation of RNA and DNA: From In Vitro Characterization to In Vivo Function. Nucleic Acids Res (2021) 49(7):3634-50. doi: 10.1093/nar/ gkab136

18. Kim G, Ison G, McKee AE, Zhang H, Tang S, Gwise T, et al. FDA Approval Summary: Olaparib Monotherapy in Patients With Deleterious Germline BRCA-Mutated Advanced Ovarian Cancer Treated With Three or More Lines of Chemotherapy. Clin Cancer Res (2015) 21(19):4257-61. doi: 10.1158/1078-0432.CCR-15-0887

19. Colombo I, Lheureux S, Oza AM. Rucaparib: A Novel PARP Inhibitor for BRCA Advanced Ovarian Cancer. Drug Design Dev Ther (2018) 12:605-17. doi: 10.2147/DDDT.S130809

20. Balasubramaniam S, Beaver JA, Horton S, Fernandes LL, Tang S, Horne HN et al. FDA Approval Summary: Rucaparib for the Treatment of Patients With Deleterious BRCA Mutation-Associated Advanced Ovarian Cancer. Clin Cancer Res (2017) 23(23):7165-70. doi: 10.1158/1078-0432.CCR-171337

21. McCann KE, Hurvitz SA. Advances in the Use of PARP Inhibitor Therapy for Breast Cancer. Drugs Context (2018) 7:212540. doi: 10.7573/dic.212540

22. Song Z, Wang Y, Xiao Q, Yu Z, Zhao L, Wu H, et al. Poly(ADP-Ribose) Polymerase-3 Overexpression Is Associated With Poor Prognosis in Patients With Breast Cancer Following Chemotherapy. Oncol Lett (2018) 16 (5):5621-30. doi: 10.3892/ol.2018.9398

23. Tao L, Wang X, Zhou Q. Long Noncoding RNA SNHG16 Promotes the Tumorigenicity of Cervical Cancer Cells by Recruiting Transcriptional Factor SPI1 to Upregulate PARP9. Cell Biol Int (2020) 44(3):773-84. doi: 10.1002/cbin.11272

24. Aguiar RC, Yakushijin Y, Kharbanda S, Salgia R, Fletcher JA, Shipp MA. BAL Is a Novel Risk-Related Gene in Diffuse Large B-Cell Lymphomas That Enhances Cellular Migration. Blood (2000) 96(13):4328-34. doi: 10.1182/ blood.V96.13.4328

25. Cheng L, Li Z, Huang YZ, Zhang X, Dai XY, Shi L, et al. TCDD-Inducible Poly-ADP-Ribose Polymerase (TIPARP), A Novel Therapeutic Target Of Breast Cancer. Cancer Manage Res (2019) 11:8991-9004. doi: 10.2147/ CMAR.S219289

26. Palavalli Parsons LH, Challa S, Gibson BA, Nandu T, Stokes MS, Huang D, et al. Identification of PARP-7 Substrates Reveals a Role for MARylation in Microtubule Control in Ovarian Cancer Cells. eLife (2021) 10:e60481. doi: 10.7554/eLife.60481

27. Ghosh R, Roy S, Kamyab J, Danzter F, Franco S. Common and Unique Genetic Interactions of the Poly(ADP-Ribose) Polymerases PARP1 and 
PARP2 With DNA Double-Strand Break Repair Pathways. DNA Repair (2016) 45:56-62. doi: 10.1016/j.dnarep.2016.06.001

28. Beck C, Robert I, Reina-San-Martin B, Schreiber V, Dantzer F. Poly(ADPRibose) Polymerases in Double-Strand Break Repair: Focus on PARP1, PARP2 and PARP3. Exp Cell Res (2014) 329(1):18-25. doi: 10.1016/ j.yexcr.2014.07.003

29. Huang SM, Mishina YM, Liu S, Cheung A, Stegmeier F, Michaud GA, et al. Tankyrase Inhibition Stabilizes Axin and Antagonizes Wnt Signalling. Nature (2009) 461(7264):614-20. doi: 10.1038/nature08356

30. Karlberg T, Klepsch M, Thorsell AG, Andersson CD, Linusson A, Schuler H. Structural Basis for Lack of ADP-Ribosyltransferase Activity in Poly(ADPRibose) Polymerase-13/Zinc Finger Antiviral Protein. J Biol Chem (2015) 290(12):7336-44. doi: 10.1074/jbc.M114.630160

31. Wang Z, Michaud GA, Cheng Z, Zhang Y, Hinds TR, Fan E, et al. Recognition of the Iso-ADP-Ribose Moiety in Poly(ADP-Ribose) by WWE Domains Suggests a General Mechanism for Poly(ADP-Ribosyl) Ation-Dependent Ubiquitination. Genes Dev (2012) 26(3):235-40. doi: $10.1101 / \mathrm{gad} .182618 .111$

32. Karras GI, Kustatscher G, Buhecha HR, Allen MD, Pugieux C, Sait F, et al. The Macro Domain Is an ADP-Ribose Binding Module. EMBO J (2005) 24 (11):1911-20. doi: 10.1038/sj.emboj.7600664

33. Aguiar RC, Takeyama K, He C, Kreinbrink K, Shipp MA. B-Aggressive Lymphoma Family Proteins Have Unique Domains That Modulate Transcription and Exhibit Poly(ADP-Ribose) Polymerase Activity. J Biol Chem (2005) 280(40):33756-65. doi: 10.1074/jbc.M505408200

34. Yang CS, Jividen K, Spencer A, Dworak N, Ni L, Oostdyk LT, et al. Ubiquitin Modification by the E3 Ligase/ADP-Ribosyltransferase Dtx3L/Parp9. Mol Cell (2017) 66(4):503-16 e5. doi: 10.1016/j.molcel.2017.04.028

35. Robson M, Im SA, Senkus E, Xu B, Domchek SM, Masuda N, et al. Olaparib for Metastatic Breast Cancer in Patients With a Germline BRCA Mutation. New Engl J Med (2017) 377(6):523-33. doi: 10.1056/NEJMoa1706450

36. Litton JK, Rugo HS, Ettl J, Hurvitz SA, Gonçalves A, Lee KH, et al. Talazoparib in Patients With Advanced Breast Cancer and a Germline BRCA Mutation. New Engl J Med (2018) 379(8):753-63. doi: 10.1056/ NEJMoa 1802905

37. Rehman FL, Lord CJ, Ashworth A. Synthetic Lethal Approaches to Breast Cancer Therapy. Nat Rev Clin Oncol (2010) 7(12):718-24. doi: 10.1038/ nrclinonc. 2010.172

38. De Soto JA, Wang X, Tominaga Y, Wang RH, Cao L, Qiao W, et al. The Inhibition and Treatment of Breast Cancer With Poly (ADP-Ribose) Polymerase (PARP-1) Inhibitors. Int J Biol Sci (2006) 2(4):179-85. doi: 10.7150/ijbs.2.179

39. Karicheva O, Rodriguez-Vargas JM, Wadier N, Martin-Hernandez K, Vauchelles R, Magroun N, et al. PARP3 Controls TGFbeta and ROS Driven Epithelial-to-Mesenchymal Transition and Stemness by Stimulating a TG2-Snail-E-Cadherin Axis. Oncotarget (2016) 7(39):6410923. doi: $10.18632 /$ oncotarget.11627

40. Ikeda Y, Kiyotani K, Yew PY, Kato T, Tamura K, Yap KL, et al. Germline PARP4 Mutations in Patients With Primary Thyroid and Breast Cancers. Endocrine-related Cancer (2016) 23(3):171-9. doi: 10.1530/ERC-15-0359

41. Zhang L, Cao J, Dong L, Lin H. TiPARP Forms Nuclear Condensates to Degrade HIF-1alpha and Suppress Tumorigenesis. Proc Natl Acad Sci USA (2020) 117(24):13447-56. doi: 10.1073/pnas.1921815117

42. Fang Q, Yao S, Luo G, Zhang X. Identification of Differentially Expressed Genes in Human Breast Cancer Cells Induced by 4-Hydroxyltamoxifen and Elucidation of Their Pathophysiological Relevance and Mechanisms. Oncotarget (2018) 9(2):2475-501. doi: 10.18632/oncotarget.23504

43. Tang X, Zhang H, Long Y, Hua H, Jiang Y, Jing J. PARP9 Is Overexpressed in Human Breast Cancer and Promotes Cancer Cell Migration. Oncol Lett (2018) 16(3):4073-7. doi: 10.3892/ol.2018.9124

44. Beck C, Rodriguez-Vargas JM, Boehler C, Robert I, Heyer V, Hanini N, et al. PARP3, a New Therapeutic Target to Alter Rictor/mTORC2 Signaling and Tumor Progression in BRCA1-Associated Cancers. Cell Death Differentiation (2019) 26(9):1615-30. doi: 10.1038/s41418-018-0233-1

45. Koo J, Wu X, Mao Z, Khuri FR, Sun SY. Rictor Undergoes Glycogen Synthase Kinase 3 (GSK3)-Dependent, FBXW7-Mediated Ubiquitination and Proteasomal Degradation. J Biol Chem (2015) 290(22):14120-9. doi: $10.1074 /$ jbc.M114.633057
46. Gulhati P, Bowen KA, Liu J, Stevens PD, Rychahou PG, Chen M, et al. Mtorc1 and Mtorc2 Regulate EMT, Motility, and Metastasis of Colorectal Cancer via RhoA and Racl Signaling Pathways. Cancer Res (2011) 71 (9):3246-56. doi: 10.1158/0008-5472.CAN-10-4058

47. Sharif-Askari B, Amrein L, Aloyz R, Panasci L. PARP3 Inhibitors ME0328 and Olaparib Potentiate Vinorelbine Sensitization in Breast Cancer Cell Lines. Breast Cancer Res Treat (2018) 172(1):23-32. doi: 10.1007/s10549018-4888-6

48. Prawira A, Munusamy P, Yuan J, Chan CHT, Koh GL, Shuen TWH, et al. Assessment of PARP4 as a Candidate Breast Cancer Susceptibility Gene. Breast Cancer Res Treat (2019) 177(1):145-53. doi: 10.1007/s10549-019-05286-w

49. Brown EJ, Baltimore D. Essential and Dispensable Roles of ATR in Cell Cycle Arrest and Genome Maintenance. Genes Dev (2003) 17(5):615-28. doi: 10.1101/gad.1067403

50. Wang Z, Grosskurth SE, Cheung T, Petteruti P, Zhang J, Wang X, et al. Pharmacological Inhibition of PARP6 Triggers Multipolar Spindle Formation and Elicits Therapeutic Effects in Breast Cancer. Cancer Res (2018) 78(23):6691-702. doi: 10.1158/0008-5472.CAN-18-1362

51. Rundle S, Bradbury A, Drew Y, Curtin NJ. Targeting the ATR-CHK1 Axis in Cancer Therapy. Cancers (2017) 9(5):41. doi: 10.3390/cancers9050041

52. Couse JF, Korach KS. Estrogen Receptor Null Mice: What Have We Learned and Where Will They Lead Us? Endocr Rev (1999) 20(3):358-417. doi: 10.1210/edrv.20.3.0370

53. Rasmussen M, Tan S, Somisetty VS, Hutin D, Olafsen NE, Moen A, et al. PARP7 and Mono-ADP-Ribosylation Negatively Regulate Estrogen Receptor Alpha Signaling in Human Breast Cancer Cells. Cells (2021) 10 (3):623. doi: 10.3390/cells10030623

54. Fujimoto M, Takii R, Takaki E, Katiyar A, Nakato R, Shirahige K, et al. The HSF1-PARP13-PARP1 Complex Facilitates DNA Repair and Promotes Mammary Tumorigenesis. Nat Commun (2017) 8(1):1638. doi: 10.1038/ s41467-017-01807-7

55. Ma Y, Zhang D, Wu H, Li P, Zhao W, Yang X, et al. Circular RNA PRKCI Silencing Represses Esophageal Cancer Progression and Elevates Cell Radiosensitivity Through Regulating the miR-186-5p/PARP9 Axis. Life Sci (2020) 259:118168. doi: 10.1016/j.lfs.2020.118168

56. Sun X, Zhang Y, Chu M, Wang L, Shen H, Zhang Z, et al. PARP6 Acts as an Oncogene and Positively Regulates Survivin in Gastric Cancer. Int J Clin Exp Pathol (2018) 11(5):2364-71.

57. Marton J, Fodor T, Nagy L, Vida A, Kis G, Brunyanszki A, et al. PARP10 (ARTD10) Modulates Mitochondrial Function. PloS One (2018) 13(1): e0187789. doi: 10.1371/journal.pone.0187789

58. Tang B, Zhang Y, Wang W, Qi G, Shimamoto F. PARP6 Suppresses the Proliferation and Metastasis of Hepatocellular Carcinoma by Degrading XRCC6 to Regulate the Wnt/beta-Catenin Pathway. Am J Cancer Res (2020) 10(7):2100-13.

59. Tian L, Yao K, Liu K, Han B, Dong H, Zhao W, et al. PLK1/NF-kappaB Feedforward Circuit Antagonizes the Mono-ADP-Ribosyltransferase Activity of PARP10 and Facilitates HCC Progression. Oncogene (2020) 39 (15):3145-62. doi: 10.1038/s41388-020-1205-8

60. Honda S, Minato M, Suzuki H, Fujiyoshi M, Miyagi H, Haruta M, et al. Clinical Prognostic Value of DNA Methylation in Hepatoblastoma: Four Novel Tumor Suppressor Candidates. Cancer Sci (2016) 107(6):812-9. doi: $10.1111 /$ cas. 12928

61. Yao N, Chen Q, Shi W, Tang L, Fu Y. PARP14 Promotes the Proliferation and Gemcitabine Chemoresistance of Pancreatic Cancer Cells Through Activation of NF-kappaB Pathway. Mol Carcinogenesis (2019) 58(7):1291302. doi: $10.1002 / \mathrm{mc} .23011$

62. Wang H, Li S, Luo X, Song Z, Long X, Zhu X. Knockdown of PARP6 or Survivin Promotes Cell Apoptosis and Inhibits Cell Invasion of Colorectal Adenocarcinoma Cells. Oncol Rep (2017) 37(4):2245-51. doi: 10.3892/ or.2017.5441

63. Qi G, Kudo Y, Tang B, Liu T, Jin S, Liu J, et al. PARP6 Acts as a Tumor Suppressor via Downregulating Survivin Expression in Colorectal Cancer. Oncotarget (2016) 7(14):18812-24. doi: 10.18632/oncotarget.7712

64. Tuncel H, Tanaka S, Oka S, Nakai S, Fukutomi R, Okamoto M, et al. PARP6, a Mono(ADP-Ribosyl) Transferase and a Negative Regulator of Cell Proliferation, Is Involved in Colorectal Cancer Development. Int J Oncol (2012) 41(6):2079-86. doi: 10.3892/ijo.2012.1652 
65. Wu H, Li Y, Hou Q, Zhou R, Li Z, Wu S, et al. Singlecell Intratumoral Stemness Analysis Reveals the Involvement of Cell Cycle and DNA Damage Repair in Two Different Types of Esophageal Cancer. Oncol Rep (2019) 41 (6):3201-8. doi: 10.3892/or.2019.7117

66. Ambrosini G, Adida C, Altieri DC. A Novel Anti-Apoptosis Gene, Survivin, Expressed in Cancer and Lymphoma. Nat Med (1997) 3(8):917-21. doi: $10.1038 / \mathrm{nm} 0897-917$

67. Zhao Y, Hu X, Wei L, Song D, Wang J, You L, et al. PARP10 Suppresses Tumor Metastasis Through Regulation of Aurora A Activity. Oncogene (2018) 37(22):2921-35. doi: 10.1038/s41388-018-0168-5

68. Wang LH, Xiang J, Yan M, Zhang Y, Zhao Y, Yue CF, et al. The Mitotic Kinase Aurora-A Induces Mammary Cell Migration and Breast Cancer Metastasis by Activating the Cofilin-F-Actin Pathway. Cancer Res (2010) 70 (22):9118-28. doi: 10.1158/0008-5472.CAN-10-1246

69. D'Assoro AB, Liu T, Quatraro C, Amato A, Opyrchal M, Leontovich A, et al. The Mitotic Kinase Aurora-a Promotes Distant Metastases by Inducing Epithelial-to-Mesenchymal Transition in ERalpha(+) Breast Cancer Cells. Oncogene (2014) 33(5):599-610. doi: 10.1038/onc.2012.628

70. Shao C, Qiu Y, Liu J, Feng H, Shen S, Saiyin H, et al. PARP12 (ARTD12) Suppresses Hepatocellular Carcinoma Metastasis Through Interacting With FHL2 and Regulating its Stability. Cell Death Dis (2018) 9(9):856. doi: 10.1038/s41419-018-0906-1

71. Dahan J, Levillayer F, Xia T, Nouet Y, Werts C, Fanton d'Andon M, et al. LIM-Only Protein FHL2 Is a Negative Regulator of Transforming Growth Factor Betal Expression. Mol Cell Biol (2017) 37(10):e00636-16. doi: 10.1128/MCB.00636-16

72. Xu J, Lamouille S, Derynck R. TGF-Beta-Induced Epithelial to Mesenchymal Transition. Cell Res (2009) 19(2):156-72. doi: 10.1038/cr.2009.5

73. Thiery JP, Acloque H, Huang RY, Nieto MA. Epithelial-Mesenchymal Transitions in Development and Disease. Cell (2009) 139(5):871-90. doi: 10.1016/j.cell.2009.11.007

74. Iansante V, Choy PM, Fung SW, Liu Y, Chai JG, Dyson J, et al. PARP14 Promotes the Warburg Effect in Hepatocellular Carcinoma by Inhibiting JNK1-Dependent PKM2 Phosphorylation and Activation. Nat Commun (2015) 6:7882. doi: 10.1038/ncomms8882

75. Golan T, Hammel P, Reni M, Van Cutsem E, Macarulla T, Hall MJ, et al. Maintenance Olaparib for Germline BRCA-Mutated Metastatic Pancreatic Cancer. New Engl J Med (2019) 381(4):317-27. doi: 10.1056/NEJMoa1903387

76. Alimirzaie S, Mohamadkhani A, Masoudi S, Sellars E, Boffetta P, Malekzadeh R, et al. Mutations in Known and Novel Cancer Susceptibility Genes in Young Patients With Pancreatic Cancer. Arch Iranian Med (2018) 21(6):228-33.

77. Long NP, Lee WJ, Huy NT, Lee SJ, Park JH, Kwon SW. Novel Biomarker Candidates for Colorectal Cancer Metastasis: A Meta-Analysis of In Vitro Studies. Cancer Inf (2016) 15(Suppl 4):11-7. doi: 10.4137/CIN.S40301

78. Ma YS, Huang T, Zhong XM, Zhang HW, Cong XL, Xu H, et al. Proteogenomic Characterization and Comprehensive Integrative Genomic Analysis of Human Colorectal Cancer Liver Metastasis. Mol Cancer (2018) 17(1):139. doi: 10.1186/s12943-018-0890-1

79. Vasaikar S, Huang C, Wang X, Petyuk VA, Savage SR, Wen B, et al. Proteogenomic Analysis of Human Colon Cancer Reveals New Therapeutic Opportunities. Cell (2019) 177(4):1035-49 e19. doi: 10.1016/j.cell.2019.03.030

80. Wang TT, Lu J, Xu L, Wu H, Lin D, Wu Z, et al. Whole Genome Sequencing of Colorectal Neuroendocrine Tumors and in-Depth Mutational Analyses. Med Oncol (Northwood London England) (2020) 37(6):56. doi: 10.1007/ s12032-020-01356-y

81. Wu CF, Xiao M, Wang YL, Threadgill MD, Li M, Tang Y, et al. PARP10 Influences the Proliferation of Colorectal Carcinoma Cells, a Preliminary Study. Molekuliarnaia Biol (2020) 54(2):252-61. doi: 10.31857/S0026898420020184

82. Gunderson CC, Moore KN. Olaparib: An Oral PARP-1 and PARP-2 Inhibitor With Promising Activity in Ovarian Cancer. Future Oncol (London England) (2015) 11(5):747-57. doi: 10.2217/fon.14.313

83. Boussios S, Karihtala P, Moschetta M, Abson C, Karathanasi A, Zakynthinakis-Kyriakou N, et al. Veliparib in Ovarian Cancer: A New Synthetically Lethal Therapeutic Approach. Investigational New Drugs (2020) 38(1):181-93. doi: 10.1007/s10637-019-00867-4

84. Boussios S, Abson C, Moschetta M, Rassy E, Karathanasi A, Bhat T, et al. Poly (ADP-Ribose) Polymerase Inhibitors: Talazoparib in Ovarian Cancer and Beyond. Drugs ReD (2020) 20(2):55-73. doi: 10.1007/s40268-02000301-8

85. Weberpals JI, Pugh TJ, Marco-Casanova P, Goss GD, Andrews Wright N, Rath P, et al. Tumor Genomic, Transcriptomic, and Immune Profiling Characterizes Differential Response to First-Line Platinum Chemotherapy in High Grade Serous Ovarian Cancer. Cancer Med (2021) 10(9):3045-58. doi: $10.1002 /$ cam 4.3831

86. Goode EL, Chenevix-Trench G, Song H, Ramus SJ, Notaridou M, Lawrenson $\mathrm{K}$, et al. A Genome-Wide Association Study Identifies Susceptibility Loci for Ovarian Cancer at 2q31 and 8q24. Nat Genet (2010) 42(10):874-9. doi: $10.1038 /$ ng. 668

87. Sharma Saha S, Gentles L, Bradbury A, Brecht D, Robinson R, O'Donnell R, et al. Genomic, Transcriptomic, and Functional Alterations in DNA Damage Response Pathways as Putative Biomarkers of Chemotherapy Response in Ovarian Cancer. Cancers (2021) 13(6):1420. doi: 10.3390/cancers13061420

88. Challa S, Khulpateea BR, Nandu T, Camacho CV, Ryu KW, Chen H, et al. Ribosome ADP-Ribosylation Inhibits Translation and Maintains Proteostasis in Cancers. Cell (2021) 184(17):4531-46.e26. doi: 10.1016/ j.cell.2021.07.005

89. Schleicher EM, Galvan AM, Imamura-Kawasawa Y, Moldovan GL, Nicolae CM. PARP10 Promotes Cellular Proliferation and Tumorigenesis by Alleviating Replication Stress. Nucleic Acids Res (2018) 46(17):8908-16. doi: $10.1093 /$ nar/gky658

90. Zhao Y, Liang X, Wei L, Liu Y, Liu J, Feng H, et al. RNF114 Suppresses Metastasis Through Regulation of PARP10 in Cervical Cancer Cells. Cancer Commun (London England) (2021) 41(2):187-91. doi: 10.1002/cac2.12132

91. Todorova T, Bock FJ, Chang P. PARP13 Regulates Cellular mRNA PostTranscriptionally and Functions as a Pro-Apoptotic Factor by Destabilizing TRAILR4 Transcript. Nat Commun (2014) 5:5362. doi: 10.1038/ ncomms6362

92. Kischkel FC, Lawrence DA, Chuntharapai A, Schow P, Kim KJ, Ashkenazi A. Apo2L/TRAIL-Dependent Recruitment of Endogenous FADD and Caspase-8 to Death Receptors 4 and 5. Immunity (2000) 12(6):611-20. doi: 10.1016/s1074-7613(00)80212-5

93. Sprick MR, Weigand MA, Rieser E, Rauch CT, Juo P, Blenis J, et al. FADD/ MORT1 and Caspase-8 Are Recruited to TRAIL Receptors 1 and 2 and Are Essential for Apoptosis Mediated by TRAIL Receptor 2. Immunity (2000) 12 (6):599-609. doi: 10.1016/s1074-7613(00)80211-3

94. Merino D, Lalaoui N, Morizot A, Schneider P, Solary E, Micheau O. Differential Inhibition of TRAIL-Mediated DR5-DISC Formation by Decoy Receptors 1 and 2. Mol Cell Biol (2006) 26(19):7046-55. doi: 10.1128/MCB.00520-06

95. Marsters SA, Sheridan JP, Pitti RM, Huang A, Skubatch M, Baldwin D, et al. A Novel Receptor for Apo2L/TRAIL Contains a Truncated Death Domain. Curr Biol: CB (1997) 7(12):1003-6. doi: 10.1016/s0960-9822(06)00422-2

96. LeBlanc HN, Ashkenazi A. Apo2L/TRAIL and Its Death and Decoy Receptors. Cell Death Differentiation (2003) 10(1):66-75. doi: 10.1038/ sj.cdd. 4401187

97. Walter P, Ron D. The Unfolded Protein Response: From Stress Pathway to Homeostatic Regulation. Science (2011) 334(6059):1081-6. doi: 10.1126/ science. 1209038

98. Clarke HJ, Chambers JE, Liniker E, Marciniak SJ. Endoplasmic Reticulum Stress in Malignancy. Cancer Cell (2014) 25(5):563-73. doi: 10.1016/ j.ccr.2014.03.015

99. Oakes SA, Papa FR. The Role of Endoplasmic Reticulum Stress in Human Pathology. Annu Rev Pathol (2015) 10:173-94. doi: 10.1146/annurev-pathol012513-104649

100. Wang J, Zhu C, Song D, Xia R, Yu W, Dang Y, et al. Epigallocatechin-3Gallate Enhances ER Stress-Induced Cancer Cell Apoptosis by Directly Targeting PARP16 Activity. Cell Death Discov (2017) 3:17034. doi: 10.1038/cddiscovery.2017.34

101. Long F, Yang D, Wang J, Wang Q, Ni T, Wei G, et al. SMYD3-PARP16 Axis Accelerates Unfolded Protein Response and Mediates Neointima Formation. Acta Pharm Sin B (2021) 11(5):1261-73. doi: 10.1016/j.apsb.2020.12.010

102. Kunhiraman H, Ramachandran V, Edatt L, Sameer Kumar VB. Regulation of Poly ADP-Ribosylation of VEGF by an Interplay Between PARP-16 and TNKS-2. Mol Cell Biochem (2020) 471(1-2):15-27. doi: 10.1007/s11010-02003746-2 
103. Bachmann SB, Frommel SC, Camicia R, Winkler HC, Santoro R, Hassa PO. DTX3L and ARTD9 Inhibit IRF1 Expression and Mediate in Cooperation With ARTD8 Survival and Proliferation of Metastatic Prostate Cancer Cells. Mol Cancer (2014) 13:125. doi: 10.1186/1476-4598-13-125

104. More P, Goedtel-Armbrust U, Shah V, Mathaes M, Kindler T, AndradeNavarro MA, et al. Drivers of Topoisomerase II Poisoning Mimic and Complement Cytotoxicity in AML Cells. Oncotarget (2019) 10(51):5298312. doi: 10.18632/oncotarget.27112

105. Lee MK, Cheong HS, Koh Y, Ahn KS, Yoon SS, Shin HD. Genetic Association of PARP15 Polymorphisms With Clinical Outcome of Acute Myeloid Leukemia in a Korean Population. Genet Testing Mol Biomarkers (2016) 20(11):696-701. doi: 10.1089/gtmb.2016.0007

106. Barbarulo A, Iansante V, Chaidos A, Naresh K, Rahemtulla A, Franzoso G, et al. Poly(ADP-Ribose) Polymerase Family Member 14 (PARP14) Is a Novel Effector of the JNK2-Dependent Pro-Survival Signal in Multiple Myeloma. Oncogene (2013) 32(36):4231-42. doi: 10.1038/onc.2012.448

107. Han L, Shi H, Luo Y, Sun W, Li S, Zhang N, et al. Gene Signature Based on B Cell Predicts Clinical Outcome of Radiotherapy and Immunotherapy for Patients With Lung Adenocarcinoma. Cancer Med (2020) 9(24):9581-94. doi: 10.1002/cam4.3561

108. Quan JJ, Song JN, Qu JQ. PARP3 Interacts With FoxM1 to Confer Glioblastoma Cell Radioresistance. Tumour Biol: J Int Soc Oncodevelopmental Biol Med (2015) 36(11):8617-24. doi: 10.1007/s13277-015-3554-4

109. Juszczynski P, Kutok JL, Li C, Mitra J, Aguiar RC, Shipp MA. BAL1 and BBAP Are Regulated by a Gamma Interferon-Responsive Bidirectional Promoter and Are Overexpressed in Diffuse Large B-Cell Lymphomas With a Prominent Inflammatory Infiltrate. Mol Cell Biol (2006) 26 (14):5348-59. doi: 10.1128/MCB.02351-05

110. Camicia R, Bachmann SB, Winkler HC, Beer M, Tinguely M, Haralambieva E, et al. BAL1/ARTD9 Represses the Anti-Proliferative and Pro-Apoptotic IFNgamma-STAT1-IRF1-P53 Axis in Diffuse Large B-Cell Lymphoma. J Cell Sci (2013) 126(Pt 9):1969-80. doi: 10.1242/jcs.118174

111. Cho SH, Ahn AK, Bhargava P, Lee CH, Eischen CM, McGuinness O, et al. Glycolytic Rate and Lymphomagenesis Depend on PARP14, an ADP Ribosyltransferase of the B Aggressive Lymphoma (BAL) Family. Proc Natl Acad Sci USA (2011) 108(38):15972-7. doi: 10.1073/pnas.1017082108

112. Mehrotra P, Riley JP, Patel R, Li F, Voss L, Goenka S. PARP-14 Functions as a Transcriptional Switch for Stat6-Dependent Gene Activation. J Biol Chem (2011) 286(3):1767-76. doi: 10.1074/jbc.M110.157768

113. Smirnikhina SA, Lavrov AV, Chelysheva EY, Adilgereeva EP, Shukhov OA, Turkina A, et al. Whole-Exome Sequencing Reveals Potential Molecular Predictors of Relapse After Discontinuation of the Targeted Therapy in Chronic Myeloid Leukemia Patients. Leuk Lymphoma (2016) 57(7):1669-76. doi: 10.3109/10428194.2015.1132420

114. Schenkel LB, Molina JR, Swinger KK, Abo R, Blackwell DJ, Lu AZ, et al. A Potent and Selective PARP14 Inhibitor Decreases Protumor Macrophage Gene Expression and Elicits Inflammatory Responses in Tumor Explants.
Cell Chem Biol (2021) 28(8):1158-68.e13. doi: 10.1016/j.chembiol.2021. 02.010

115. Nicolae CM, Aho ER, Choe KN, Constantin D, Hu HJ, Lee D, et al. A Novel Role for the Mono-ADP-Ribosyltransferase PARP14/ARTD8 in Promoting Homologous Recombination and Protecting Against Replication Stress. Nucleic Acids Res (2015) 43(6):3143-53. doi: 10.1093/nar/gkv147

116. Dhoonmoon A, Schleicher EM, Clements KE, Nicolae CM, Moldovan GL. Genome-Wide CRISPR Synthetic Lethality Screen Identifies a Role for the ADP-Ribosyltransferase PARP14 in DNA Replication Dynamics Controlled by ATR. Nucleic Acids Res (2020) 48(13):7252-64. doi: 10.1093/nar/gkaa508

117. Frias C, Garcia-Aranda C, De Juan C, Moran A, Ortega P, Gomez A, et al. Telomere Shortening Is Associated With Poor Prognosis and Telomerase Activity Correlates With DNA Repair Impairment in Non-Small Cell Lung Cancer. Lung Cancer (2008) 60(3):416-25. doi: 10.1016/j.lungcan.2007.11.001

118. Yamada T, Horimoto H, Kameyama T, Hayakawa S, Yamato H, Dazai M, et al. Constitutive Aryl Hydrocarbon Receptor Signaling Constrains Type I Interferon-Mediated Antiviral Innate Defense. Nat Immunol (2016) 17 (6):687-94. doi: 10.1038/ni.3422

119. Pan D, Kobayashi A, Jiang P, Ferrari de Andrade L, Tay RE, Luoma AM, et al. A Major Chromatin Regulator Determines Resistance of Tumor Cells to T Cell-Mediated Killing. Science (2018) 359(6377):770-5. doi: 10.1126/ science.aaol710

120. Gozgit JM, Vasbinder MM, Abo RP, Kunii K, Kuplast-Barr KG, Gui B, et al. PARP7 Negatively Regulates the Type I Interferon Response in Cancer Cells and its Inhibition Triggers Antitumor Immunity. Cancer Cell (2021) 39 (9):1214-26.e10. doi: 10.1016/j.ccell.2021.06.018

121. Falchook GS, Patel MR, Yap TA, Mceachern K, Johnson ML. A First-inHuman Phase 1 Study of a Novel PARP7 Inhibitor RBN-2397 in Patients With Advanced Solid Tumors. J Clin Oncol (2021) 39(15_suppl):3000-. doi: 10.1200/JCO.2021.39.15_suppl.3000

Conflict of Interest: The authors declare that the research was conducted in the absence of any commercial or financial relationships that could be construed as a potential conflict of interest.

Publisher's Note: All claims expressed in this article are solely those of the authors and do not necessarily represent those of their affiliated organizations, or those of the publisher, the editors and the reviewers. Any product that may be evaluated in this article, or claim that may be made by its manufacturer, is not guaranteed or endorsed by the publisher.

Copyright (๑) 2021 Sha, Gan, Zou, Wu and Feng. This is an open-access article distributed under the terms of the Creative Commons Attribution License (CC BY). The use, distribution or reproduction in other forums is permitted, provided the original author(s) and the copyright owner(s) are credited and that the original publication in this journal is cited, in accordance with accepted academic practice. No use, distribution or reproduction is permitted which does not comply with these terms. 